\title{
Implementation of Chopped-Fiber Composite Material as Hot-Gas Nozzle Insulation
}

\author{
Hossam KAMAL \\ Lecturer of mechanical engineering \\ Obour Institutes \\ Belbis, Egypt
}

\author{
Ossama Kamal MAHMOUD \\ Lecturer of mechanical engineering \\ Egyptian Academy for Engineering and Advanced \\ Technology \\ Cairo, Egypt
}

\author{
Abdel-Nasser ZAYED \\ Professor of mechanical engineering \\ Cairo, Egypt
}

\begin{abstract}
This work represents a complete practical project for the thermal insulation of hot-gas nozzles using chopped fiber composites. It starts with the selection of the insulation material from the available on-the-shelf material combinations, where four materials are available and it is required which one should be used. This is done using mechanical and thermal characterization of materials. Then, a computational work is performed to determine the working conditions of the nozzle by solving the nozzle flow. Another computational work is done to optimize the insulation thickness using finite element thermostructural analysis. After that, the nozzle prototype is manufactured with thermal probe-holes to verify the calculations.
\end{abstract} Nozzle

Keywords- Chopped Fiber, Thermal Insulation, Hot-Gas

\section{INTRODUCTION}

Hot-gas nozzles have many applications in our life; hot-gas welding, furnaces, rocket motors, ...etc. One of their problems is the insulation of the nozzle structure from the gas side as the they work in sever conditions for normal metallic materials including high temperature, pressure and gas velocity. Thermal insulation represents a suitable feasible solution for these working conditions. Composite materials are ideal for thermal insulation and chopped-fiber composites have an additional feature of easy manufacturing on complex shapes.

The mechanical properties of short fiber studied by Blumentritt et al. [1] showed that the modulus of the composite is proportional to the fiber concentration and modulus of the fiber. Zhu et al. [2] proved that the reinforcement morphology had an effect on the mechanical properties of the short fiber composites. They reinforced bone shaped short fibers instead of the normal fibers which showed a significant improvement in the yielding strength and young's modulus with an effective crack bridging. Jacob et al. [3] studied the effect of fiber length on the energy absorption of the carbon fiber composite, and concluded that shorter fiber lengths leads to higher specific energy absorptions. Garoushi et al. [4] conducted various studies on fiber lengths varying form $1 \mathrm{~mm}-6 \mathrm{~mm}$, and reported that the fiber length of $5 \mathrm{~mm}$ demonstrated good mechanical properties for the resin used. These studies showed an improvement in mechanical properties with an increase in fiber volume fraction. From these studies [2-4] it is clear that the fiber length and fiber volume fraction are critical parameters in determining the properties of the composite. When compared to continuous fibers reinforced composites, short fibers reinforced composites can be easily processed with affordable cost. The most important factors in the short fibers reinforcement are fiber dispersion and fiber aspect ratio. The homogeneous fiber dispersion is the most important factor to enhance the mechanical properties.

Chopped-fiber composites have excellent thermal properties and easily formed on complex shapes. There are a lot of literatures from early 50s of last century. Warja [5] introduced the Aerojet-General Corporation evaluation program on behalf of US Air Force and NASA to develop reinforced ablative composite solid rocket nozzles through the use of inexpensive materials and low-cost fabricating techniques. In that program eight materials were evaluated and it was concluded that the best results can be achieved by using carbon or graphite reinforce inserts in the throat section. In the same line, Winya et al. [6] studied the ablation, mechanical and thermal properties of a rocket motor insulation made of phenolic/ fiber matrix composites. They studied the heat and corrosion properties of phenolic/ fiber matrix laminate with different fiber between fiberglass and locally available synthetic fibers and suggested the use of phenolic/synthetic fiber composite as reinforcement in a composite may improve the thermal insulation in nozzle of rocket motor. Recently, Nassar and Nassar [7] investigated The effect of addition of fine size from Silicon Carbide (SiC) with different weight percentage on the mechanical, thermal, and physical properties of chopped carbon fiber reinforced epoxy composite. They used SiC and epoxy manufactured in Egypt. They showed that the optimum properties for epoxy composite are obtained for 15 wt.\% from fine SiC content in addition to 25 wt.\% chopped carbon fiber-reinforced epoxy composites.

The present work aims to evaluate four materials to be used as an insulation material for a hot-gas nozzle. The first part introduces the experimental work carried out to characterize the materials from points of view of mechanical, thermal and ablative properties. Then, the next part depicts the computational work elaborated to find out the working environment of the nozzle using the classical nozzle theory and the thermo-structural analysis performed to analyze and optimize the insulation thickness. The final part represents the experimental verification of the results through measurement of temperature at convergent and divergent parts of the nozzle and comparing these results to the computed results. 


\section{MATERIAL CHARACTERIZATION}

Four chopped-fiber composites were selected to obtain their characteristics and select the suitable one; Basalt with phenol (B-Ph), fiber-glass with phenol (FG-Ph), Carbon-fiber with phenol (CF-Ph), and Carbon-fiber with epoxy (CF-E). The four combinations are prepared and cured as instructed by Advani \& Hsiao [8]. The final product is a square sheet of $30 \mathrm{~cm}$ side and $3 \mathrm{~mm}$ thickness. This sheet is used to cut-out the required specimen needed for mechanical tests on universal test machine (ZWICK Z050) and those required for thermal tests using Differential Scanning Calorimetry (DSC) and ThermoMechanical Analysis (TMA). To obtain the mechanical properties of these materials four tests are carried out; tensile test, three-point bending, compression test, and the hardness test. For tensile, the test specimen are cut according to JANNAF standard to avoid slipping while testing. For the other mechanical tests, the specimens were cut to make strips with dimensions $250 \times 25 \times 3.5 \mathrm{~mm}$ according to ISO 3039:2010. Tapping material is used at the both ends of the specimens. Tensile tests are carried out in four temperatures (-40, 25, 100, and $200{ }^{\circ} \mathrm{C}$ ) with at least three specimens for each test point. The other mechanical tests are carried out in room temperature $25^{\circ} \mathrm{C}$.

Figure 1 depicts the values of maximum strength versus the temperature for each material. It is noted that while CF-E illustrates around three times the value of maximum strength at cold and room temperature, this deteriorates to very low values at elevated temperatures. On the other hand, the other three materials based on phenol resin (FG-Ph, CF-Ph, and B-Ph) exhibit more stable (narrow-band) behaviour of maximum strength. In order to detect the effect of temperature on maximum strength at $200{ }^{\circ} \mathrm{C}$ based on its value at normal temperature $\left(25^{\circ} \mathrm{C}\right)$, Table 1 illustrates that B-Ph loses $86.8 \%$, FG-Ph loses 83.8\%, CF-Ph loses 77.8\%, and CF-E loses 96.8 $\%$. This leads to the exclusion of epoxy-based material as the required part will serve in elevated temperature conditions. Table 2 shows the results of three-point bending and hardness tests. It depicts that CF-E has the maximum strength then FG$\mathrm{Ph}, \mathrm{CF}-\mathrm{Ph}$, and the least one is $\mathrm{B}-\mathrm{Ph}$. Regarding the flexibility of materials through their strain, FG-Ph exhibits the least flexibility, then CF-Ph, B-Ph, and CF-E is the most flexible one.

Table 1 - Percentage change of maximum strength based on its value at 25 oC

\begin{tabular}{|c|c|c|c|c|}
\hline \multirow{2}{*}{ Temp. } & \multicolumn{4}{|c|}{ Materials } \\
\cline { 2 - 5 } & $B-P h$ & $F G-P h$ & $C F-P h$ & $C F-E$ \\
\hline-40.0 & $-42.6 \%$ & $-9.0 \%$ & $-11.7 \%$ & $3.2 \%$ \\
\hline 25.0 & $0.0 \%$ & $0.0 \%$ & $0.0 \%$ & $0.0 \%$ \\
\hline 100.0 & $-76.5 \%$ & $-47.6 \%$ & $-59.7 \%$ & $-92.6 \%$ \\
\hline 200.0 & $-86.8 \%$ & $-83.8 \%$ & $-77.8 \%$ & $-96.8 \%$ \\
\hline
\end{tabular}

Table 2 - Results of three-point bending and hardness tests at 25 oC

\begin{tabular}{|c|c|c|c|c|}
\hline Parameter & B-Ph & FG-Ph & CF-Ph & CF-E \\
\hline Max. Stress [MPa] & 20.9 & 45.4 & 36.0 & 54.3 \\
\hline Max. strain \% & 0.82 & 0.57 & 0.58 & 0.92 \\
\hline Break Stress [MPa] & 20.0 & 32.4 & 24.5 & 37.5 \\
\hline Strain at break \% & 0.9667 & 0.62 & 0.86 & 1.1 \\
\hline hardness [Shore D] & 82 & 78 & 80 & 90 \\
\hline
\end{tabular}

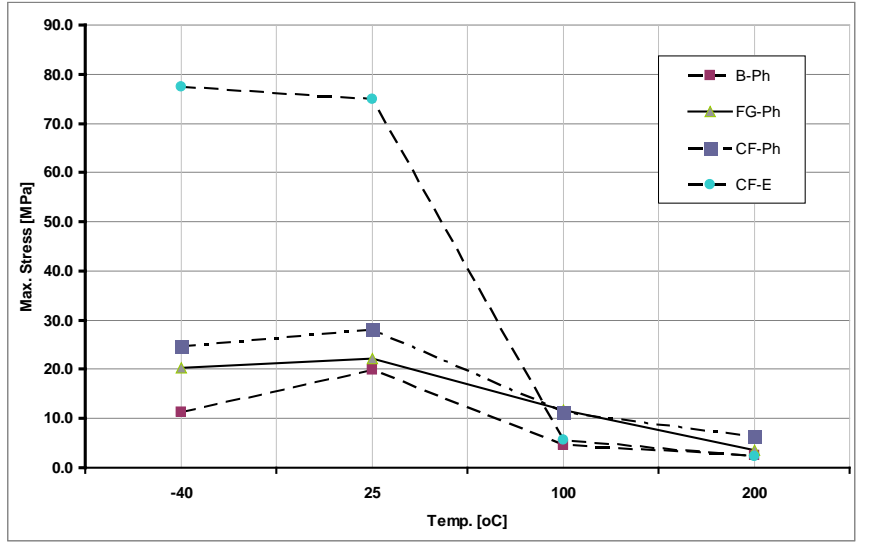

Figure 1 - Maximum Strength Versus Temperature (Tensile Test)

Thermal properties of chopped composites are important parameters for determining application and use of this category of materials. ASTM Method E1952 [9] describes the measurement of thermal conductivity by Modulated DSC. It is applicable to homogeneous, non-porous solid materials with a thermal conductivity in the limited range of 0.10 to $1.0(\mathrm{~W} / \mathrm{m}$ ${ }^{\circ} \mathrm{C}$ ) and a temperature range from 0 to $90{ }^{\circ} \mathrm{C}$. Samples of diameters $5 \mathrm{~mm}$ are prepared to be used with the DSC Q2000 apparatus to determine the thermal conductivity and samples of $8 \times 8 \mathrm{~mm}$ are prepared to be used with the TMA Q400 apparatus to determine thermal expansion coefficient. Table 3 illustrates the results of measurement of thermal conductivity and coefficient of thermal expansion (CTE). The apparent heat capacity is proportional to the square root of the thermal conductivity of the material as introduced by Marcus \& Blaine [10]. It can be remarked that CF-Ph has the smallest CTE with a considerable value relative to the other materials. Thermal conductivity results show that $\mathrm{CF}-\mathrm{Ph}$ has the smallest value, however, the four materials have close values with maximum variation of $22 \%$ between highest and lowest values.

Table 3 - Thermal properties of the tested materials

\begin{tabular}{|c|c|c|c|c|}
\hline & B-Ph & FG-Ph & CF-Ph & CF-E \\
\hline $\begin{array}{c}\text { Thermal conductivity K } \\
{\left[\mathrm{W} / \mathrm{m} /{ }^{\circ} \mathrm{C}\right]}\end{array}$ & 0.1720 & 0.1846 & 0.1590 & 0.1942 \\
\hline $\begin{array}{c}\text { Coefficient of thermal } \\
\text { expansion CTE } \\
{\left[\mu \mathrm{m} / \mathrm{m} /{ }^{\circ} \mathrm{C}\right]}\end{array}$ & -179.9 & -146.6 & -273.7 & 1049 \\
\hline
\end{tabular}

Combining the mechanical and thermal properties of the tested materials, FG-Ph is selected as it exhibits the best combination of properties. As the selected material is used in an hot-gas nozzle insulation, a final ablation test is conducted to insure the ability of material to withstand the continuous heat flux at elevated temperature. A specimen of $\varnothing 110 \mathrm{~mm}$ of FG$\mathrm{Ph}$ is layered on a steel plate with embedded thermocouples to measure the temperature. The specimen is exposed to Oxyacetylene flame at $2300{ }^{\circ} \mathrm{C}$ and it is held for $60 \mathrm{~s}$. The weight is measured for the sample before and after the test to calculate the decrease in the materials.

Result is illustrated in Figure 2 showing that the measured temperature reached $73.96{ }^{\circ} \mathrm{C}$ after 81.7 seconds. 


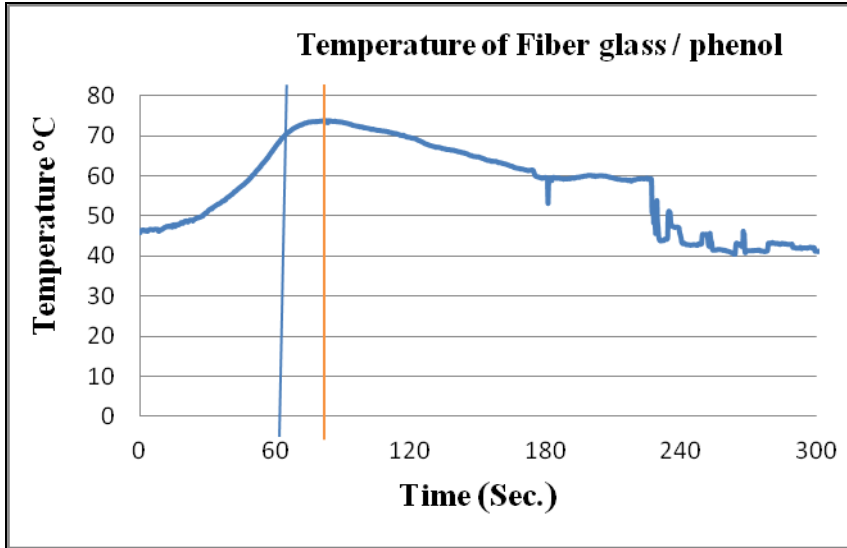

Figure 2 - Ablation test of FG-Ph insulation

\section{COMPUTATIONAL SIMULATION}

After selecting the suitable material for insulation, the material thickness should be optimized. This is done by computational simulation of the nozzle structure under thermal and flow parameters loads using ANSYS V14. The nozzle geometric constrains are: an outer inlet diameter of $182 \mathrm{~mm}$, an outer outlet diameter of $75 \mathrm{~mm}$ and an overall length of not more than $150 \mathrm{~mm}$. First step is to apply the nozzle theory to calculate the flow conditions at the outlet and check if these conditions are satisfactory to the purpose of the nozzle. According to Sutton and Biblarz [11] in a convergent-divergent nozzle, the area of any section $A_{x}$ is related to the throat area $A_{t}$ by:

$\frac{A_{t}}{A_{x}}=\frac{V_{t} v_{x}}{V_{x} v_{t}}=\left(\frac{k+1}{2}\right)^{1 /(k-1)}\left(\frac{p_{x}}{p_{1}}\right)^{1 / k} \sqrt{\left(\frac{k+1}{k-1}\right)\left[1-\left(\frac{p_{x}}{p_{1}}\right)^{(k-1) / k}\right]}$

The terms of the equation are $V$ the specific volume, $v$ the gas velocity, $k$ the specific heat ratio of the gases, and $p$ the pressure. The suffix $t$ indicates the throat conditions, $x$ indicates the conditions at any section located at a distance $x$ from nozzle inlet, and "1" indicates the initial conditions at nozzle inlet.

The mass flow rate through the nozzle is given by:

$\dot{m}=\frac{A_{t} v_{t}}{V_{t}}=A_{t} p_{1} k \sqrt{\frac{[2 /(k+1)]^{(k+1) /(k-1)}}{k R T_{1}}}$

with $R$ is gas constant of the exhaust gases, and $T$ is the temperature of gases.

Optimizing the flow condition for adapted nozzle having an atmospheric pressure at outlet gives a convergent nozzle angle of $120^{\circ}$ and a divergent angle of $24^{\circ}$. The gases have a temperature range of $3800{ }^{\circ} \mathrm{C}$ to $1480{ }^{\circ} \mathrm{C}$ through the nozzle, while the pressure decreases from 70 bars at inlet to 2.2 bars at outlet. At the throat, the temperature is $2880{ }^{\circ} \mathrm{C}$, the pressure is 38 bars, and the specific gas ratio is 1.261.

These calculations represent the inputs to the thermostructural analysis of the nozzle body. The finite element model of the nozzle is built using ANSYS modeler based on axisymmetric analysis. As the final step of the work is to verify experimentally the designed nozzle, two thermal-probe holes are considered to measure the temperature of the nozzle in depth. At the entrance the depth of hole is $27 \mathrm{~mm}$ while the hole depth at the exit is $17 \mathrm{~mm}$. about $8 \mathrm{~mm}$ of composite is left between the end of the hole and the internal surfaces. Simplifying the model to reduce the number of elements which will reduce the time of solution, only a revolved cross section of $15^{\circ}$ is used including the places of the two holes used to measure the temperature. The mesh is optimized for temperature tolerance of 10-2 with 3875 tetrahedral elements. A transient thermal analysis is carried out and it is found that the insulation material cannot withstand the flow conditions at throat. Hence, the nozzle design is modified to include a graphite (5890) insert at the throat. Figure 3 illustrates the final finite element mesh with graphite insert and thermal probe holes. The outer light green colour shows the steel part, the middle blue-grey colour designates the FG-Ph insulation, and the inner grey colour illustrates the graphite insert. The graphite insert has a thermal conductivity of 121.1 and $69.20 \mathrm{~W} / \mathrm{m} .{ }^{\circ} \mathrm{C}$ in $\mathrm{x}$ and $\mathrm{y}$ directions at $20^{\circ} \mathrm{C}$, and of 27.68 and $25.95 \mathrm{~W} / \mathrm{m} .{ }^{\circ} \mathrm{C}$ in $\mathrm{x}$ and $\mathrm{y}$ directions at $2200^{\circ} \mathrm{C}$.

The thermal analysis results show that from time zero to 5 seconds the composite material is capable to resist the temperature propagation then its temperature starts to rise. After 50 seconds, the temperature of the two probe-holes has a value of only $30^{\circ} \mathrm{C}$. After 305 seconds, the probes should read $63{ }^{\circ} \mathrm{C}$. These results illustrate that the insulation FG-Ph is satisfactorily efficient. Figure 4 depicts the thermal distribution on the finite element model at 305 seconds.

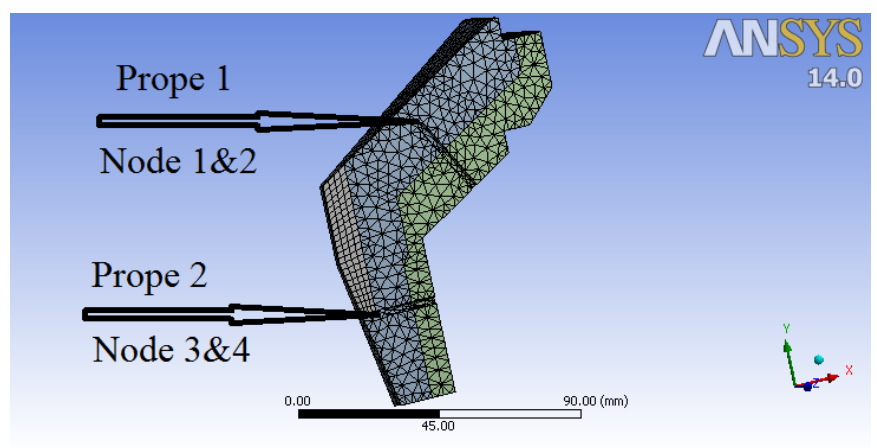

Figure 3 - Finite element model of the nozzle section

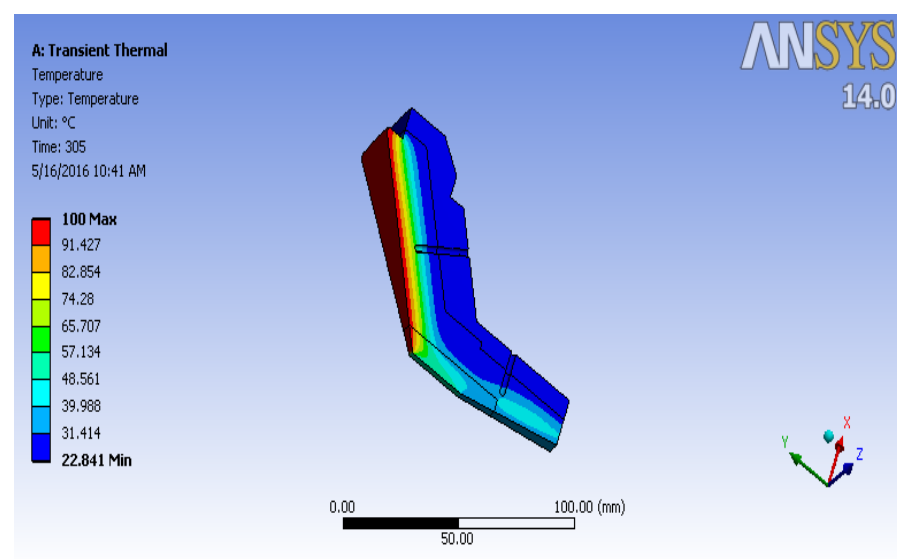

Figure 4 - Finite element of temperature distribution at $305 \mathrm{~s}$ 


\section{EXPERIMENTAL VERIFICATION}

The final step of the project is to verify the computational results with experimental work. A set of three nozzles is manufactured as a prototype to measure the temperature. The nozzles are assembled to closed chamber filled with energetic material to produce the required flow of hot gases. Each nozzle is used once and temperature at each thermal-probe hole is measured and results are averaged. Also, a pressure sensor is assembled to the closed chamber to assure same pressure for the experiments. Figure 5 shows a photo for manufactured nozzle illustrating the metal part, the insulation made of FG-Ph material, and the graphite insert.

Comparing the measured temperature from the real test at convergent-part probe with that obtained from the ANSYS, it is remarked that the two curves have the same profile and the two curves are completely identical until 120 seconds as shown in Figure 6. It is noted also that while the measured temperature continues rising, the calculated temperature tend to be fixed where the measured temperature reaches about $79{ }^{\circ} \mathrm{C}$ and the calculated temperature reaches about $63^{\circ} \mathrm{C}$. That is because the initial condition of the ANSYS after the firing period doesn't have neither real nor calculated values, so the program here consider that the temperature is dropped from initial values given during the firing to a room temperature, so the solution reach the steady state in time and values less than that measured from the real test as the hot gases still exist affecting temperature to continue rising.

At the divergent-part probe, both measured and computed solutions obey the same behavior also. The temperature started to rise until it reaches its maximum value after about 30 seconds then it tends to decrease because the exit section is free to air and the cooling condition here is faster than the cooling inside the nozzle, as shown in Figure 7. Comparing the two curves there is slight difference in the values where the computed solution reaches the maximum of $51{ }^{\circ} \mathrm{C}$ in 14.75 seconds while the measured one reaches a maximum of $49.6 \mathrm{C}$ after 15.02 seconds.

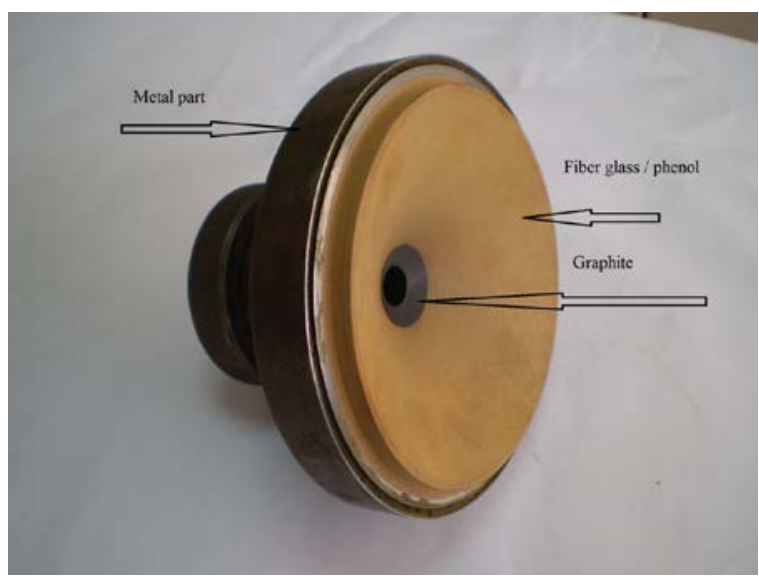

Figure 5 - The manufactured nozzle

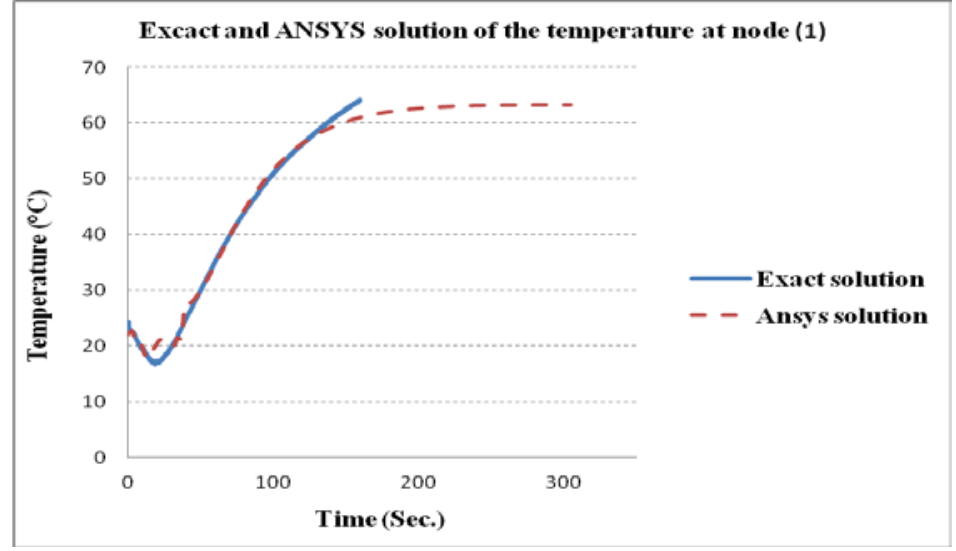

Figure 6 - Measured and calculated temperature history at convergent-part probe

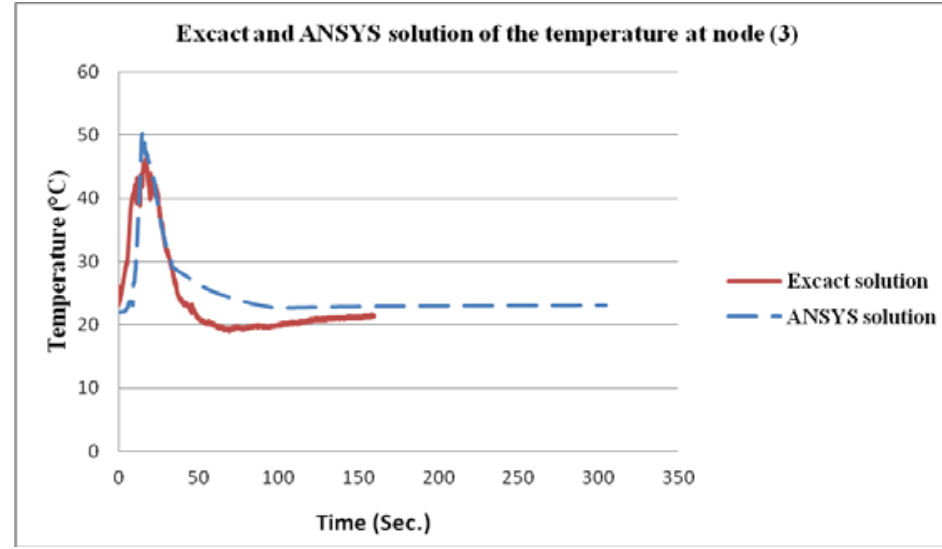

Figure 7 - Measured and calculated temperature history at divergent-part probe

\section{CONCLUSIONS}

A complete cycle of chopped-fiber composite material evaluation to be used as an insulation material of hot-gas nozzle, computational analysis and optimization, and experimental verification is carried out. Four materials are evaluated; Basalt with phenol (B-Ph), fiber-glass with phenol (FG-Ph), Carbon-fiber with phenol (CF-Ph), and Carbon-fiber with epoxy (CF-E). The characterization process indicates that FG-Ph is the most suitable material of the four. Nozzle theory is implemented and gives that the gases have a temperature range of $3800 \mathrm{oC}$ to $1480 \mathrm{oC}$ through the nozzle, while the pressure decreases from 70 bars at inlet to 2.2 bars at outlet. At the throat, the temperature is $2880 \mathrm{oC}$, the pressure is 38 bars, and the specific gas ratio is 1.261. Then, a thermo-structural analysis is carried out and leads to obligation of using a graphite insert at the throat section and the suitable insulation thickness is $8 \mathrm{~mm}$. Finally, a set of three nozzles are manufactured and prepared for temperature measurement at convergent and divergent parts. A good agreement is found between the measured temperature by the experimental work and the temperature obtained by ANSYS. 


\section{REFERENCES}

[1] B. F. Blumentritt, B. T. Vu, and S. L. Cooper, "The mechanical properties of oriented discontinuous fiber reinforced thermoplastics: I. Unidirectional fiber orientation," Polymer Engineering \& Science, vol. 14, pp. 633-640, 1974

[2] Y. T. Zhu, J. Valdez, N. Shi, M. Lovato, M. Stout, and S. Zhou, "Influence of reinforcement morphology on the mechanical properties of short-fiber composites," Processing of Metals and Advanced Materials: Modeling, Design and Properties. Edited by Li, BQ, TMS pp. 251-259, 1998

[3] G. C. Jacob, J. M. Starbuck, J. F. Fellers, and S. Simunovic, "Effect of fiber volume fraction, fiber length and fiber tow size on the energy absorption of chopped carbon fiber-polymer composites," Polymer composites, vol. 26, pp. 293-305, 2005.

[4] S. K. Garoushi, L. V. Lassila, and P. K. Vallittu, "Short fiber reinforced composite: the effect of fiber length and volume fraction," J Contemp Dent Pract, vol. 7, pp. 10-17, 2006

[5] J. J. Warja "Low-cost fabrication techniques for solid rocket nozzles", Society of Automotive Engineering Inc., National Aeronautics and Space Engineering and Manufacturing Meeting Los-Angeles Calif., October 5-9, 1970
[6] N. Winya, S. Chankapoe, C. Kiriratnikom, " Ablation, Mechanical and Thermal Properties of Fiber/Phenolic Matrix Composites", International Journal of Chemical, Molecular, Nuclear, Materials and Metallurgical Engineering Vol:6, No:9, 2012.

[7] A. Nassar and E. Nassar, " Thermo and Mechanical Properties of Fine Silicon Carbide /Chopped Carbon Fiber Reinforced Epoxy Composites", Universal Journal of Mechanical Engineering 2(9): 287292, 2014

[8] S. G. Advani and K.-T. Hsiao (editors), "Manufacturing techniques for polymer matrix composites (PMCs)", Woodhead Publishing Limited, 2012

[9] ASTM, "ASTM Test Method E1225 Thermal Conductivity of Solids by Means of the Guarded- comparative-Longitudinal Heat Flow Technique," ed. Annual Book of ASTM Standards: vol. 14.02

[10] S. M. Marcus and R. L. Blaine, "Thermal conductivity of polymers, glasses and ceramics by modulated DSC," Thermochimica Acta, vol. 243, pp. 231-239, 1994

[11] G. P. Sutton and O. Biblarz, "Rocket Propulsion Elements", John Wiley \& Sons., 7th ed., 2001 